\title{
LANGUAGE ACQUISITION IN CHILDREN WITH AUTISM
}

\section{SPECTRUM DISORDER}

\section{Calum Hartley}

\section{Background}

Autism Spectrum Disorder (ASD) is a neurodevelopmental disorder defined by profound social deficits in conjunction with restricted and repetitive behavioral tendencies (American Psychiatric Association, 2013). Epidemiological data show that ASD affects approximately $1 \%-2 \%$ of children worldwide and is diagnosed more frequently in males than females (Elsabbagh et al., 2012). Although language impairments are not a core criterion for ASD, they are a very common feature and play a central role in specifying an individual's unique presentation (American Psychiatric Association, 2013). Professional assessments are often motivated by parental concerns about delayed language acquisition (De Giacomo \& Fombonne, 1998), and a significant sub-group are minimally verbal throughout their lifetime (Pickles, Anderson, \& Lord, 2014). These individuals often present with complex communication needs and intellectual disabilities that impact their cognitive development and independence (Fernell, Eriksson, \& Gillberg, 2013). Understanding why so many children with ASD have difficulty 
acquiring language is a global research objective, and a vital precursor to the development of effective interventions.

The purpose of this chapter is to provide an up-to-date summary of several branches of research focusing on language in ASD. This chapter will briefly summarize the characteristics of language in autism, spotlight the profile of minimally verbal children, explore differences in lexical acquisition mechanisms, consider strategies for assessing language in children with ASD, and review recent advances in the development and implementation of evidence-based interventions.

\section{Language in autism: a brief overview}

Delayed language production is a common, but not universal, characteristic of ASD (Gernsbacher, Morson, \& Grace, 2015). Whereas typically developing (TD) children usually utter their first words by 12 months, children with ASD start to speak at 38 months on average, and only $30 \%-50 \%$ acquire phrase speech by 4 years (Ellis Weismer \& Kover, 2015; Howlin, 2003). Children with ASD tend to have much smaller expressive vocabularies than TD children matched on chronological age (Charman, Drew, Baird, \& Baird, 2003; Luyster, Kadlec, Carter, \& Tager-Flusberg, 2008), and many produce unusual "echolalic" utterances (immediate or delayed imitation of others' 
language) on a frequent basis (Tager-Flusberg \& Calkins, 1990). However, in comparison to TD and language-delayed control groups (e.g. late talkers) matched on language production, children with ASD do not differ in terms of their most frequently used words (Ellis Weismer et al., 2011). Current estimates indicate that $70 \%$ of children with ASD are eventually able to communicate using fluent sentences, and approximately $10 \%$ demonstrate expressive language skills that are commensurate with their chronological age (Pickles et al., 2014).

Autism also impacts children's language comprehension. Most children with ASD understand fewer words than age-matched TD children, and many are relatively more impaired in receptive than expressive language (Luyster et al., 2007, 2008). Approximately $30 \%$ of preschoolers with ASD show an unusual linguistic profile characterized by almost-equivalent receptive and expressive abilities (Hudry et al., 2010), whereas TD infants' receptive skills significantly outweigh their productive skills in every communicative domain (Adamson, 1995). Almost all children with ASD have difficulty understanding pragmatics (i.e. how language is used for social purposes) irrespective of their general linguistic competencies (Kelley, Paul, Fein, \& Naigles, 2006). This trait has been linked to general intellectual disabilities (Abbeduto \& Hesketh, 1997), impaired Theory of Mind (Baron-Cohen, 
Baldwin, \& Crowson, 1997), and deficits in executive functioning (Ozonoff et al., 2004). Yet, when matched to TD children on language comprehension, the composition of grammatical (e.g. nouns, verbs) and semantic (e.g. objects, animals) categories within their receptive vocabularies is not atypical (Charman et al., 2003). Furthermore, the acquisition of more advanced comprehension skills (e.g. understanding figurative language) by children with ASD appears to follow a normal trajectory in line with their receptive language development (Gernsbacher \& Pripas-Kapit, 2012; Norbury, 2005). Research exploring how individuals with ASD use morphology (individual units of meaningful language) and syntax (combinations of words into phrases) has yielded conflicting results. Tek, Mesite, Fein, and Naigles' (2014) growth curve analysis showed that the trajectories for morphosyntax and sentence complexity in TD children and verbal children with ASD are equivalent when differences in intercept are accounted for. In comparison to language-matched TD controls, children with ASD acquire Brown's 14 morphemes in a similar order (Brown, 1973), show minimal differences in sentence repetition and story-telling tasks, demonstrate similar understanding of wh-questions, and evidence similar use of plural and tense markers (Goodwin, Fein, \& Naigles, 2012; Naigles, Kelty, Jaffery, \& Fein, 2011; Waterhouse \& Fein, 1982). By contrast, other studies have shown that children with ASD make more morphological errors than mental-age- 
matched control groups (Bartolucci, Pierce, \& Streiner, 1980) and generate less syntactically complex spontaneous language (Eigsti, Bennetto, \& Dadlani, 2007). Eigsti and Bennetto (2009) found that children with ASD were significantly less accurate at judging the correctness of sentence grammar than TD controls matched on age, IQ, and receptive vocabulary. It is also well documented that children with ASD make frequent errors when using pronouns (e.g. "I" and "me"; Lind \& Bowler, 2009). Importantly, studies investigating variability within ASD have proposed the existence of at least two developmental profiles for spoken language; one characterized by largely intact morphosyntactic abilities, and another characterized by grammatical impairments (Roberts, Rice, \& Tager-Flusberg, 2004; Tek et al., 2014). For more detailed and comprehensive reviews of language structure in ASD, see Eigsti, de Marchena, Schuh, and Kelley (2011), Boucher (2012), and Naigles and Tek (2017).

Overall, comparisons against language-matched controls suggest that global linguistic development in autism may be delayed rather than qualitatively deviant. Linguistic milestones are achieved via a trajectory that is broadly similar to non-autistic development, and for many individuals, specific deficits tend to resolve and stabilize at mental-age-appropriate levels (Boucher, 2012; Gernsbacher et al., 2015). In addition, evidence that 
language difficulties and autistic traits are influenced by distinct genetic, environmental, and etiological factors implies that these domains may develop independently (Taylor et al., 2014). While language in ASD may have some unusual characteristics (e.g. atypical pronoun use, echolalia, absence of the normative advantage for receptive over expressive language), these features are not universal or necessarily unique to autism (Gernsbacher, Morson, \& Grace, 2016). Indeed, language development in ASD is extraordinarily heterogeneous. At one end of the spectrum, a sub-set of children achieve age-appropriate scores on most standardized language assessments, but show subtle pragmatic anomalies in naturalistic interactions (Boucher, 2012). However, a sub-set of children at the other end of the spectrum struggle to learn any language, potentially due to deviant functioning of specific lexical acquisition mechanisms (as discussed later in this chapter).

\section{Minimally verbal children with autism}

\section{Description and prevalence}

A substantial proportion of children with ASD are "minimally verbal" (Tager-Flusberg \& Kasari, 2013). The definition of "minimally verbal” is relatively broad, encompassing children who have absolutely no speech as well as those who use an extremely limited repertoire of words (5-20) for 
communicative purposes (Kasari, Brady, Lord, \& Tager-Flusberg, 2013). Language use by these children tends to be infrequent, inflexible, echolalic, and context-specific. Minimally verbal children with ASD may attempt to communicate their instrumental needs, but their reliance on non-linguistic vocalizations and restricted speech sounds can hinder their caregivers' comprehension (Tager-Flusberg, Paul, \& Lord, 2005). Difficulties communicating their needs and understanding others' communication can elicit frustration, causing children to display self-injurious behaviors and strike out aggressively, and inducing the development of behavioral rituals (Bondy \& Frost, 2002).

It was historically estimated that around 50\% of children with ASD would never develop functional phrase speech (Prizant, 1996; Rutter, 1978). However, recent literature indicates that this percentage could be decreasing. In a longitudinal study that tracked the language development of 96 children with ASD between 2 and 9 years, Anderson and colleagues (2007) reported that $29 \%$ of this population had no or few consistent words at final assessment. These children tended to have severely impaired joint attention skills early in childhood, indicating a connection between preverbal social cognition and later language outcomes (also see Yoder, Watson, \& Lambert, 2015; McDuffie, Yoder, \& Stone, 2005). More recently, Norrelgen et al. 
(2015) reported communication outcomes for 165 children with ASD aged 4 to 6.5 years. They sought to establish the proportion of children with profoundly impaired language acquisition, and explored the relationship between language and cognitive ability. The results showed that $15 \%$ of children were nonverbal, exhibiting expressive language age equivalents below 15 months with fewer than three spoken words. A further $10 \%$ were minimally verbal, with expressive language age equivalents below 24 months and the occasional use of two-word phrases. The vast majority of these children had severe intellectual disabilities, and nearly $75 \%$ had performance IQs below 50. In another recent study, Rose et al. (Rose, Trembath, Keen, \& Paynter, 2016) documented the proportion of children with ASD who were minimally verbal upon entering and exiting a community-based early intervention program that lasted 5 years. Out of 246 children, $26 \%$ exited the program using fewer than five spoken words. Taken together, these contemporary statistics suggest that children with minimal-to-no spoken language comprise $25 \%-30 \%$ of the ASD population. This reduction in prevalence may be attributed to numerous factors, including 1. the broadening of diagnostic criteria, 2. increasing numbers of verbal children receiving diagnoses, and 3. increased access to early interventions (Tager-Flusberg \& Kasari, 2013). 


\section{Minimally verbal or preverbal?}

Children are often categorized as minimally verbal if they do not acquire spoken language before 5 years (Tager-Flusberg \& Kasari, 2013). However, some children who meet this criterion eventually develop functional and fluent language at a later stage of development. Thus, it may be that a child with significantly delayed language acquisition is "preverbal" rather than truly minimally verbal. Although preverbal children lack functional speech, they possess crucial pre-linguistic skills that ultimately scaffold functional language acquisition (DiStefano \& Kasari, 2016). The early identification of children as preverbal or minimally verbal has important implications for intervention programs and prediction of later outcomes; however, accurate discrimination is hindered by extreme variability in linguistic development within ASD (DiStefano \& Kasari, 2016).

Research has strived to identify factors that determine whether a nonverbal child will successfully develop language after receiving interventions (Kasari et al., 2013; Tager-Flusberg \& Kasari, 2013). In comparison to peers who remain minimally verbal, preverbal children with ASD tend to use more basic gestures, produce more consonant sounds, imitate more frequently, and show increased joint attention (Ellis Weismer \& Kover, 2015; Woynaroski, Yoder, $\&$ Watson, 2016). These foundational social-communicative abilities are 
known to statistically predict language outcomes in children who are identified as minimally verbal at a young age (e.g. Woynaroski et al., 2016). Several studies have reported that children with higher nonverbal IQs usually display superior linguistic skills, indicating a predictive relationship between language development and general cognitive functioning in ASD (Kjelgaard \& Tager-Flusberg, 2001; Norrelgen et al., 2015). However, language impairments in minimally verbal children with ASD are often more severe than predicted based on their IQ (Lord, Risi, \& Pickles, 2004), suggesting that linguistic heterogeneity in ASD cannot be attributed to variability in cognitive functioning exclusively. Promisingly, recent advances in neuroimaging research have revealed that minimally verbal and preverbal children may be distinguished based on brain structure and neural activity. Children with more positive language outcomes experience greater cortical activation in response to speech than children who remain minimally verbal (Kuhl et al., 2013; Lombardo et al., 2015). Minimally verbal children also show atypical structural development in brain regions associated with language development, including the left middle temporal gyrus and arcuate fasciculus (Riva et al., 2011; Wan, Marchina, Norton, \& Schlaug, 2012). Importantly, these studies indicate that severe communication impairments exhibited by minimally verbal children may be caused by a fundamental deficit in 
language acquisition that is separable from their ASD diagnosis (i.e. comorbid developmental language disorder; Tager-Flusberg \& Joseph, 2003). Despite their prevalence, minimally verbal children are often neglected in empirical research (Tager-Flusberg \& Kasari, 2013). Studying children with profound language impairments is essential to advance and inform theoretical understanding of language acquisition mechanisms, highlight barriers to language learning, and inform the design and implementation of effective interventions (Eigsti et al., 2011). As linguistic milestones (e.g. age of first words and phrases) strongly predict developmental trajectories for speech and adaptive skills (Howlin, Goode, Hutton, \& Rutter, 2004; Kover et al., 2016), investigating the nature and causes of severe language deficits in ASD is of clear intellectual and practical importance.

\section{Differences in lexical acquisition mechanisms}

In order to generate effective interventions that promote language development in children with ASD, it is vital to understand which processes that support language acquisition are impaired or functionally atypical. Provision of an in-depth and comprehensive account of this expansive topic is beyond the scope of this chapter (see Arunachalam \& Luyster, 2016, for a focused review), so we will concentrate on evidence from a few significant mechanisms: attentional preferences for speech, use of linguistic and social 
cues that facilitate the identification of word meanings, lexical retention, and the application of constraints that inform the generalization of words to novel category members.

\section{Preferences for speech}

TD infants are born with an innate preference for speech over non-speech sounds (Vouloumanos \& Werker, 2007; Shultz \& Vouloumanos, 2010). They also prefer infant-directed speech (IDS), which is characterized by slower speed, greater pitch variation, simplified sentence structure, longer repetitive intonational structures, and higher frequency (Fernald, 1985; Gleitman, Newport, \& Gleitman, 1984), over speech directed at adults. The strength of infants' preference for speech predicts lexical development (Vouloumanos \& Curtin, 2014; Weisleder \& Fernald, 2013), and IDS supports language learning by facilitating word segmentation (Floccia et al., 2016) and providing redundant cues to grammatical structure (Singh, Nestor, Parikh, \& Yull, 2009). Conversely, children with ASD do not show reliable preferences for speech over non-speech sounds (Curtin \& Vouloumanos, 2013), or IDS over adult-directed speech (Droucker, Curtin, \& Vouloumanos, 2013). The absence of these preferences may have important consequences for language acquisition as they statistically predict speech comprehension and production in children with ASD both concurrently and longitudinally (Paul, Chawarska, 
Fowler, Cicchetti, \& Volkmar, 2007; Watson, Baranek, Roberts, David, \& Perryman, 2010). Although diminished preference for IDS may characterize ASD at a group level, and potentially represent an early diagnostic marker (Filipe, Watson, Vicente, \& Frota, 2017), there is considerable heterogeneity across individuals, and further research is required to fully understand the causes and consequences of this deficit (Droucker et al., 2013).

Infants are immersed in a world of language from birth, and the experience of listening to speech narrows their auditory perception so they become attuned to their native language (Kuhl, Williams, Lacerda, Stevens, \& Lindblom, 1992). In their classic study, Werker and Tees (1999) demonstrated that infants are capable of discriminating speech sounds from native and nonnative languages with similar accuracy until approximately 8 months. However, by 10 months, infants' sensitivity to non-native sounds decreases, while their discriminatory perception of native sounds is retained. By contrast, heightened perception of sounds over the lifetime is a common trait in ASD (Jones et al., 2009). In comparison to controls, children and adults with ASD show increased sensitivity and accuracy when categorizing pitch and discriminating auditory stimuli including word pairs, lexical tones, pure tones, non-words, and non-speech sounds (Bonnel et al., 2010; Heaton, Hudry, Ludlow, \& Hill, 2008; Järvinen-Pasley, Wallace, Ramus, Happé, \& 
Heaton, 2008). It is possible that generally heightened auditory sensitivity has a negative effect on early language acquisition, as the perceptual system may not specialize to the sounds of one's native language (Kuhl et al., 2008). Indeed, evidence suggests that children with ASD with superior discrimination of auditory frequencies are more likely to be delayed in speaking their first words (Bonnel et al., 2010; Jones et al., 2009). This may be because perceptual attuning to language facilitates the detection of word boundaries and syntactic structures, and enhanced auditory sensitivity inhibits the efficiency of these abilities (Eigsti \& Fein, 2013). Thus, it could be that language delay or impairments in ASD result from failure of the auditory perceptual system to functionally or structurally specialize in processing speech during infancy.

\section{Identifying meaning: mutual exclusivity and social cues}

To learn and use language, children must establish lasting relationships between discrete phonological patterns - words - and their associated semantic categories. Once a spoken word has been identified by the auditory perceptual system, the process of mapping to meaning involves several mechanisms: 1. referent selection; identification of a word's intended meaning, 2. retention; storage of the word-referent pairing in long-term memory enabling later retrieval, and 3. generalization; appropriate extension 
of the word to new category members. Below we will review research that has investigated the integrity of these processes in ASD.

The "dynamic associative account” (McMurray, Horst, \& Samuelson, 2012) a leading theory of neurotypical word learning - posits that referent selection and retention are underpinned by separate fast and slow learning mechanisms. In the context of the naming event, referent selection (fast mapping) requires solving the problem of referential ambiguity (there are often multiple potential targets for a newly heard word; Quine, 1960) and involves narrowing children's attention down to a single target (the intended referent). This attentional narrowing can be directed by numerous sources of information, including universal linguistic constraints. One such constraint is "mutual exclusivity" (ME), the assumption that a given word has only one referent (Markman, 1990). By 2 years of age, TD children apply ME to assign novel words to unfamiliar objects when presented alongside familiar objects with known names (Carey, 1978; Markman \& Wachtel, 1988). Several studies investigating the use of ME by children with ASD suggest that this heuristic is intact and employed by individuals across the spectrum. Preissler and Carey (2005) presented minimally verbal children with pairs of pictures and objects - one familiar and one unfamiliar - and asked them to identify the referent of a novel word. The participants spontaneously applied ME by 
mapping the novel name to the unfamiliar object on $82 \%$ of trials. In a study by de Marchena, Eigsti, Worek, Ono, and Snedeker (2011), high-functioning children with ASD were presented with two unfamiliar objects. One object was ostensively named, and children were asked to identify the referent of a second novel word. Participants correctly identified the unnamed object as the referent of the second novel word on approximately $90 \%$ of trials, thus demonstrating effective use of ME (also see Parish-Morris, Hennon, HirshPasek, Golinkoff, \& Tager-Flusber, 2007). Studies have found that other heuristics, such as the noun bias (the tendency to map novel words onto objects rather than actions), are also intact in ASD (Swenson, Kelley, Fein, \& Naigles, 2007). Together, these findings present convincing evidence that children with ASD, including those with severe linguistic and cognitive impairments, can accurately identify the referents of newly heard words based on lexical assumptions.

TD children also utilize social-pragmatic cues to solve the problem of referential ambiguity. From an early age, TD infants are aware that a novel word is likely to refer to whatever object is currently the focus of a speaker's attention (Bloom, 2002) and spontaneously infer referential intent from gaze, gestures, and emotional affect (Baldwin, 1993; Nappa, Wessel, McEldoon, Gleitman, \& Trueswell, 2009; Tomasello, Strosberg, \& Akhtar, 1996). 
Baldwin's (1991) seminal study revealed that TD infants aged 16-19 months will spontaneously consult a speaker's face when they hear a novel word and identify a referent based on their direction of gaze. However, children must be sensitive to social cues if they are to inform language acquisition. It is traditionally argued that word learning deficits in ASD stem from diagnosisdefining impairments in social communication (e.g. Baron-Cohen et al., 1997). Children with ASD show population-level impairments in intention reading (Griffin, 2002; Hartley \& Allen, 2014a, 2015a), eye contact and social orienting (Nadig, Ozonoff, Young, Rozga, Sigman, \& Rogers, 2007; Osterling, Dawson, \& Munson, 2002), gaze following (Gillespie-Lynch, Elias, Escudero, Hutman, \& Johnson, 2013), and joint attention (Mundy, Sigman, \& Kasari, 1990). Based on evidence that these abilities statistically predict concurrent and longitudinal language outcomes in ASD (Anderson et al., 2007; McDuffie et al., 2005), it has been theorized that language acquisition may depend on the severity of social-communicative deficits (Thurm, Lord, Lee, \& Newschaffer, 2007).

Perhaps surprisingly, studies investigating whether children with ASD are sensitive to social cues when identifying word referents report mixed findings. An early study by Baron-Cohen et al. (1997) discovered that children with ASD and profound language impairments mapped novel labels 
onto objects that were the focus of their attention, rather than a speaker's intended referents. By contrast, ability-matched TD children and intellectually disabled children utilized the speaker's direction of gaze as a cue to mapping. Preissler and Carey (2005) replicated Baron-Cohen's findings with another sample of minimally verbal children with ASD. In a more recent study, Gliga et al. (2012) found that linguistically impaired children with ASD could follow gaze to the correct referents of words, but then failed to map word-referent relationships. These results suggest that word learning in language-impaired children with ASD is not informed by cues to a speaker's referential intent.

On the other hand, studies with high-functioning samples suggest that children with ASD do attend to social cues when identifying word meanings. Employing the same paradigm as Baron-Cohen et al. (1997), Luyster and Lord (2009) found that young children with ASD and TD children matched on vocabulary and verbal mental age (approx. 2 years) did not significantly differ on their use of social cues when mapping novel word-referent relationships. In McGregor and colleagues' study (McGregor, Rost, Arenas, Farris-Trimble, \& Stiles, 2013), children with ASD and TD controls matched on chronological age and nonverbal IQ watched a video of an adult speaking an unfamiliar word while positioned in front of three unfamiliar objects. 
When the adult directed her gaze at the intended referent, children with ASD and TD controls mapped the word correctly on $74 \%$ and $73 \%$ of trials respectively (also see Norbury, Griffiths, \& Nation, 2010). Another study by Bean Ellawadi and McGregor (2016) investigated whether children with ASD would follow an experimenter's gaze to map new word-object relationships over multiple trials. In comparison to TD controls matched on receptive vocabulary, few children with ASD attended to gaze on the first trial. However, across several trials, the populations did not differ on their attendance to gaze or their fast mapping accuracy.

In light of growing evidence, it is now widely argued that children with ASD who develop functional language skills are sensitive to social-communicative cues when learning words in laboratory environments. However, it is unclear to what extent children's sensitivity to social cues in highly controlled settings translates to naturalistic word learning. It has recently been argued that social cues facilitate word learning insofar as they direct children's attention to referent objects and away from competitors, thus increasing the accuracy of associative learning mechanisms, rather than providing a window to the speaker's referential intentions (Axelsson, Churchley, \& Horst, 2012). Children with diminished social motivation may not reliably attend to gaze or gestural cues when deciphering the meanings of words in natural learning 
environments (Chevallier, Kohls, Troiani, Brodkin, \& Schultz, 2012), or they may be distracted or overwhelmed by alternative sensory input. In support of this hypothesis, Tenenbaum, Amso, Righi, and Sheinkopf (2017) found that holding a target object near a speaker's mouth facilitated learning in children with ASD, whereas holding the object far from their mouth hindered performance (children's attention was divided between the two features of the visual scene, reducing the strength of the encoded word-referent association). In addition, Akechi and colleagues (2011) found that children with ASD aged 6-12 reliably mapped a novel word to a speaker's object (the intended referent) only when it was more perceptually salient than an object they themselves were holding.

Overall, the balance of evidence suggests that referent selection is not pervasively impaired in ASD, and therefore cannot account for severe language acquisition difficulties. However, minimally verbal children with ASD (and possibly more verbal individuals) may not use social cues to disambiguate unfamiliar word meanings in natural contexts, therefore increasing their dependency on lexical heuristics (e.g. ME) and consequently raising the probability of mapping errors.

\section{Retention}


Although referent selection may be functional in ASD, it is important to acknowledge that correct mapping-to-meaning does not constitute word learning. Horst and colleagues have repeatedly demonstrated that TD children forget new words just 5 minutes after performing at ceiling on a referent selection task (Horst \& Samuelson, 2008; Horst, Scott, \& Pollard, 2010; Axelsson et al., 2012). This suggests that long-term word learning is the result of a separate mechanism. According to dynamic associative theory, word retention (slow learning) is underpinned by basic learning mechanisms that are highly sensitive to cross-situational statistics (McMurray et al., 2012). Over multiple learning instances, children gradually accumulate knowledge of how words map onto objects or actions in their environment. As children's referent selection skills develop with age, they experience more precise wordreferent activation patterns that increase the accuracy and speed of learning (McMurray et al., 2012).

To date, lexical retention in ASD has received relatively little attention in comparison to referent selection. However, a small number of studies suggest that children with ASD may have specific difficulty retaining word-referent relationships. Evidence from Bedford et al. (2013) indicates that this deficit could relate to broader social-communicative impairments. In their study, TD 2-year-olds' retention of newly learned word-referent relationships 
significantly improved when they received corrective and reinforcing social feedback. By contrast, retention in 2-year-olds at high risk of developing ASD did not benefit from social feedback, and this deficit was associated with smaller receptive vocabularies. The authors propose that failure to learn from social input may inhibit vocabulary development in children who develop ASD. On the other hand, Norbury et al. (2010) reported that highfunctioning children with ASD could retain word-object mappings as accurately as TD controls; however, they remembered significantly less semantic information about referents over time. Another possibility is that ASD impairs children's ability to track cross-situational relationships between words and their referents over time and contexts. While recent studies suggest that ASD does not affect statistical learning when processing visual stimuli (Roser, Aslin, McKenzie, Zahra, \& Fiser, 2015) or segmenting speech streams (Obeid, Brooks, Powers, Gillespie-Lynch, \& Lum, 2016), the ambiguity and complexity inherent in vocabulary development may place unique strain on associative learning mechanisms. In one study that has investigated cross-situational word learning in ASD, McGregor and colleagues (2013) found this ability to be impaired in children with significant language deficits. In sum, future research should explore the possibility that language-impaired children with ASD have a specific deficit in lexical retention following referent selection. 


\section{Generalization}

To use language flexibly, children must learn how to appropriately generalize words to previously unseen members of the same semantic category. TD children begin encoding word-referent relationships at approximately 6 months (Friedrich \& Friederici, 2011), and the majority of the earliestacquired words refer to object categories that are well organized by shape (Samuelson \& Smith, 1999; Perry \& Samuelson, 2011). As children map a particular noun to additional category members, they quickly realize that every "X" is "X-shaped" (Samuelson \& Smith, 1999; Smith, Jones, Landau, Gershkoff-Stowe, \& Samuelson, 2002). By approximately 24 months, TD children infer the higher-order rule that noun-referent relationships are constrained by shape, and thus generalize newly learned words to novel objects based on this feature, rather than other perceptual properties (e.g. color, size, texture; Landau, Smith, \& Jones, 1988). The emergence of this “shape bias" coincides with children's acquisition of approximately 50-150 count nouns (Gershkoff-Stowe \& Smith, 2004; Samuelson \& Smith, 1999), suggesting a link to statistical regularities in children's early vocabularies. Smith and colleagues (2002) propose that the process of learning object names selectively tunes children's attention to shape, which in turn accelerates their acquisition of new object names. The shape bias is underpinned by categorization - the cognitive process that organizes 
information into conceptual groups and enables the evaluation of new information based on existing concepts (Klinger \& Dawson, 2001). TD infants group objects through the abstraction of prototypes which represent the "central tendency" of categories (Younger, 1990). If the global shape of a newly encountered object (e.g. a Porsche 911) is sufficiently similar to a stored prototype (e.g. the car basic-level category), a child may extend the label for that prototype (e.g. "car") to the unfamiliar entity (Son, Smith, \& Goldstone, 2006).

It is well documented that children with ASD struggle to generalize information and behaviors across different contexts (Happé \& Frith, 2006). This difficulty may also manifest in the extension of verbal labels to novel referents. Using a preferential looking paradigm, Tek and colleagues (Tek, Jaffery, Fein, \& Naigles, 2008) tested whether children with ASD aged 2 to 3 years evidenced an attentional bias to shape over 12 months. Children viewed an unfamiliar object before being presented with two test objects (a target that matched the first object on shape but not color, plus a foil that matched on color but not shape). In "naming trials", the first object was assigned a novel label, and children were asked to identify which test object was also a referent of the word. Despite developing sizeable vocabularies over the year (exceeding 100 count nouns), children with ASD did not show preferential 
looking towards the shape-match test object. By comparison, TD participants matched on expressive language looked significantly longer at the shapematch once they had acquired 50 count nouns in their productive vocabularies. In a follow-up investigation employing the same task, Potrzeba, Fein, and Naigles (2015) tested larger samples over 20 months. Again, they found that children with ASD did not extend novel words based on shape at any stage, whereas TD controls evidenced a shape bias at the initial assessment (aged 20 months). The results from these two studies indicate a dissociation between vocabulary size and the maxims governing word learning in ASD. In a study by Hartley and Allen (2014b), language-impaired children with ASD were taught the name for an unfamiliar picture, and then sorted pictures and objects according to whether they were also referents of the newly learned label. The analyses showed that children with ASD extended labels to items that matched depicted objects on shape and color, but also frequently generalized to items that matched on only shape or color. Conversely, TD children matched on receptive vocabulary only extended labels to items that matched the depicted referent's shape. Although two studies suggest that shape-based label extension is unimpaired in highfunctioning individuals (McGregor \& Bean, 2012), or when verbal mental age exceeds 4.5 years (Field, Allen, \& Lewis, 2016), it may be that early 
lexical development for many children with ASD is hindered by the absence of a shape bias.

Hartley and Allen (2014b) speculate that atypical label generalization by children with ASD could be related to differences in visual processing and prototype formation. ASD is often characterized by a preference for processing visual information at a local, rather than global, level (Happé \& Frith, 2006; Mottron, Dawson, Soulières, Hubert, \& Burack, 2006). Hypersensitivity to local perceptual details may inhibit the filtering of category-irrelevant information and impact the abstraction of prototypes derived from global shape (Hartley \& Allen, 2014b). Consequently, children with ASD may not identify shape as the perceptual constraint that organizes word-referent categories, thus inhibiting the emergence of the shape bias. No studies to date have attempted to "train" the shape bias in children with ASD, but research with TD infants suggests this could be possible: Smith and colleagues (2002) successfully evoked the shape bias, plus a surge in productive vocabulary development, in 17-month-old infants after 8 weeks' play-based training that involved naming unfamiliar objects. Children with ASD may require multiple experiences with a variety of category members in order to generate explicit "rules" that correctly define category membership (Klinger \& Dawson, 2001). As such, it might be possible to teach a "shape- 
bias rule" by ostensively mapping the same name to differently colored examples of an object type (e.g. red, blue, and yellow cars), highlighting the fact that shape - rather than color - defines category membership (e.g. "car") and potentially prompting shape-based generalization to additional exemplars (e.g. green cars; Allen, Hartley, \& Cain, 2015, 2016; Twomey, Ranson, \& Horst, 2014). Exploring the efficacy and benefits of such training would be an interesting topic for future research.

In summary, language acquisition in ASD may be delayed or inhibited by the absence or impairment of fundamental mechanisms that support early learning. At a group level, children with ASD show atypical auditory perception and diminished preferences for speech (e.g. Bonnel et al., 2010; Curtin \& Vouloumanos, 2013), and individuals with linguistic deficits show limitations in their lexical referent selection, retention, and generalization (Gliga et al., 2012; Norbury et al., 2010; Potrzeba et al., 2015). However, language in ASD is characterized by exceptional heterogeneity, and the severity of differences associated with each mechanism can vary tremendously between individuals.

\section{Language assessments and interventions}

Assessing language in ASD 
Assessing the language abilities of children with ASD is a vital component of research and applied practice. Academics assess their participants' language skills for many important reasons, including sample characterization and population matching, exploration of developmental mechanisms, and identification of relationships between language and other cognitive domains. Practitioners and interventionist researchers utilize language assessments for monitoring the effects of treatments, and screening for ASD often involves testing whether a child has reached developmental milestones for receptive and expressive language (Johnson \& Myers, 2007). To obtain an accurate account of children's language abilities it is recommended that professionals utilize a range of measures (Kasari et al., 2013). Natural language samples recorded during interactions with caregivers or practitioners are an excellent vehicle for assessing multiple aspects of children's expressive language (e.g. pragmatics, phonological repertoire, grammar, lexical knowledge, etc.). Sample duration should be at least 30 minutes (possibly collected across multiple situations), thus ensuring a rich representation of the child's linguistic profile (Miller \& Chapman, 2000). The analysis of natural language can be automated via audio recording technologies (such as the Language Environment Analysis (LENA) system) that encode specific sounds and features of speech, enabling the characterization of children's languagelearning environments (Warren, Gilkerson, \& Richards, 2010). Parent-report 
assessments (e.g. questionnaires and interviews) are a useful way of gleaning information that is difficult to assess directly, although there is a risk that estimates of ability or impairment may be exaggerated (Tager-Flusberg et al., 2009). Conversely, psychometric tests enable the direct measurement of linguistic skills in comparison to standardized norms. When selecting standardized tests, assessors should seek measures with high reliability and validity that are appropriate for the developmental level of their sample (Tager-Flusberg et al., 2009). While reporting group-level descriptive statistics (e.g. mean raw scores or age equivalents) is an efficient and popular method of characterizing a sample, this approach does not accurately represent variability between individuals with ASD (Charman et al., 2003). Referring to "spoken language benchmarks" (e.g. use of preverbal communication, utterance of first words, use of word combinations, sentences, and complex language; Tager-Flusberg et al., 2009) or conducting item-level analyses (Rose et al., 2016) may be more effective ways of capturing within-sample variability. Regardless of how language is assessed, it is important to reflect on how findings from a sample generalize to the wider ASD population. Researchers should be mindful that some linguistic difficulties may be associated with certain developmental profiles (e.g. nonverbal or minimally verbal), but not others (e.g. phrase speech or complex 
language), and exploring individual differences presents an opportunity to identify predictive or precursory factors (Eigsti et al., 2011).

At a practical level, ASD can present a range of challenges when assessing language. Children with ASD often demonstrate attentional and motivational problems that affect their engagement (Eigsti et al., 2011; Koegel, Koegel, \& Smith, 1997), and the tendency to perseverate when responding can reduce an assessment's accuracy (Waterhouse \& Fein, 1982). As discomfort in an unfamiliar testing context can also impact validity and reliability, the assessment should be tailored to the child's needs (e.g. by preparing children in advance, including breaks, and utilizing reinforcers; Kasari et al., 2013). Measuring language in minimally verbal children via standardized tests brings additional problems; difficulties comprehending an experimenter's instructions and the inability to generate verbal responses often lead to floor effects (DiStefano \& Kasari, 2016; Kasari et al., 2013). Some assessments such as the Peabody Picture Vocabulary Test (Dunn \& Dunn, 2004), the British Picture Vocabulary Scale (Dunn et al., 2009), the Expressive OneWord Picture Vocabulary Test (Martin \& Brownell, 2011), and the Mullen Scales of Early Learning (Mullen, 1995) are appropriate for testing children with ASD (including minimally verbal individuals) thanks to their visual scaffolding and/or accommodation of nonverbal responding. However, the 
standardized norms for these language assessments are based on TD samples, and children with ASD may have difficulties on certain test items (Bruckner, Yoder, Stone, \& Saylor, 2007). For example, the receptive abilities of children with ASD may be underestimated by comprehension assessments that rely on social-communication skills (e.g. social orienting, pointing, joint attention). Many researchers favor parent-report measures such as the MacArthur-Bates Communicative Development Inventory (Fenson, Marchman, Thal, Reznick, \& Bates, 2006) and the Vineland Adaptive Behavior Scales (Sparrow, Cicchetti, \& Balla, 2005) because they cover development from birth, and their data are representative of children's communication in natural and familiar contexts (Kasari et al., 2013). These indirect assessments are very cost-efficient (particularly if resources, including qualified test administrators, are scarce) and provide a convenient means of acquiring initial information about a child's linguistic profile, but may lack the required sensitivity to detect effects in intervention studies (McConachie et al., 2015). For further information about assessments, see McConachie and colleagues' (2015) systematic review of measures that are often used in autism research.

\section{Language interventions for children with ASD}


As the most positive longitudinal outcomes tend to be observed in children with ASD who have functional speech before 5-6 years (Baghdadli et al., 2007), the development of expressive language is a vital priority for early interventions. Studies in the 1960s and 1970s revealed that children with ASD could successfully acquire new skills, including language, via intensive interventions based on "applied behavior analysis" (ABA) (Ferster \& DeMyer, 1962; Risley \& Wolf, 1967). ABA's core rationale is that human behavior can be modified by environmental influences, typically through operant conditioning (i.e. reinforcement of stimulus-response relationships; Lovaas et al., 1980). ABA interventions often employ "discrete trial training" (DTT); the deconstruction of target skills into isolated components that are taught individually in a sequence (e.g. imitating producing a word, followed by learning its meaning). While highly structured $\mathrm{ABA}$ interventions are popular with policy decision makers (McGrew, Ruble, \& Smith, 2016; Kasari $\&$ Smith, 2016), they have drawn criticism for promoting context-specific learning, inhibiting spontaneity, being over-dependent on prompts and situational scaffolding, and eliciting high frequencies of challenging behaviors during training (Schreibman et al., 2015).

The focus of recent research has shifted towards "naturalistic developmental behavioral interventions" (NDBIs) that integrate ABA techniques with 
theories from developmental psychology (for an extended review, see Schreibman et al., 2015). NDBIs are informed by prominent concepts of early psychological development including: 1. children's development unfolds sequentially within and across domains (Piaget, 1966), 2. children can acquire skills located in the "zone of proximal development" (i.e. just beyond their current state; Vygotsky, 1978), and 3. learning is most effective when it is developmentally meaningful (Bruner, 1983) and children are actively engaged (Gibson, 1973). NDBIs are integrated into naturally occurring activities (e.g. play, transition, meal time) and across various environments (e.g. home, school, shops) that children experience as part of their daily routine. Employing multiple instructors (e.g. therapists, teachers, parents) and diverse materials, NDBIs enable children to develop a range of abilities in a holistic fashion, rather than targeting specific skills in isolation. As the complexity of natural learning experiences increases over time, children may develop more sophisticated skills (e.g. expressive language) on top of foundational precursors (e.g. nonverbal social cognition). Crucially, the need to explicitly teach isolated skills in multiple contexts is diminished by situating learning in dynamic social interactions with naturally occurring relationships between children's responses and rewards (McGee et al., 1985). Schreibman and colleagues (2015) highlight several benefits of NDBIs including increased generalization of behaviors, improved spontaneity, 
habituation to mundane distractions in everyday environments, more efficient and natural language acquisition, and superior gains in social development. Many field-leading experts argue that NDBIs "represent state-of-the-art treatment" for young children with ASD (Schreibman et al., 2015, p. 2420). This claim is supported by evidence that NDBIs administered with high fidelity in clinics, in schools, and at home yield consistently positive outcomes for social communication (Wetherby et al., 2014; Shire et al., 2017) and potential benefits for language (Kasari, Paparella, Freeman, \& Jahromi, 2008). One NDBI that has undergone extensive empirical investigation, and is designed to promote language acquisition, is Joint Attention Symbolic Play Engagement and Regulation (JASPER; Kasari et al., 2006). The premise of JASPER is to develop foundational nonverbal skills that scaffold later language acquisition (Charman et al., 2005). In an early study by Kasari, Freeman, and Paparella (2006), 58 children with ASD aged 3-4 years with receptive and expressive language age equivalents around 20 months were randomly allocated to a NDBI condition that targeted joint attention or symbolic play, or a control group that received highly structured ABA treatment as usual. In the NDBI conditions, child-driven play-based sessions lasting 30 minutes were administered daily for 5-6 weeks. At the end of treatment, children in the NDBI conditions improved in joint attention or symbolic play (depending on the targeted skill) to the extent that they were 
significantly superior to children in the control condition. Benefits in these domains were observed in both structured assessments and naturalistic interactions with caregivers, indicating successful generalization of acquired skills across contexts. When participants were re-assessed at 6 and 12 months post-intervention, those in both NDBI conditions had improved their expressive language skills by 2.1-2.3 standard deviations (in comparison to 1 SD in the control group; Kasari et al., 2008). At 5 years post-intervention, sophistication of play at 3-4 years predicted whether children were functionally verbal. For those children who had functional speech at 8 years, expressive vocabulary was predicted by age of entry into the study (the earlier the better), assignment to the NDBI conditions, joint attention, and play. Gulsrud and colleagues' (Gulsrud, Hellemann, Freeman, \& Kasari, 2014) analyses of developmental trajectories revealed that children who pointed most often at 3-4 years had superior expressive language at follow-up. Together, these findings indicate a causal link between early socialcommunication skills and later language outcomes in ASD, and suggest that this relationship can potentially be fostered by NDBIs.

While empirical support for NDBIs is building (Schreibman et al., 2015), it is important to note that their long-term effects on language acquisition require further investigation. Many intervention studies focus on short-term 
outcomes, which tend to reveal few significant differences between approaches. For example, Hampton and Kaiser's (2016) recent meta-analysis of 26 studies including 1738 participants with ASD (aged 3.3 years on average) reported that children's short-term language outcomes are only reliably affected by who administers the intervention (treatments that are parent-only or clinician-only are less effective than those administered by parents and clinicians). Across studies, children showed modest improvements in spoken language (equivalent to a few points on a standardized assessment) immediately after receiving experimental interventions, but the authors acknowledge that such small effects may not be clinically meaningful. Longitudinal findings from NDBI studies such as Kasari et al. (2008) are certainly promising, but the field would benefit from more intervention studies with rigorous designs (e.g. randomized controlled trials) reporting long-term outcomes in speech production and comprehension. This need is particularly pressing given the general resilience of children with ASD to interventions targeting language development, despite making gains in other aspects of social communication and symptom reduction (e.g. Pickles et al., 2016). Furthermore, it should be emphasized that the effects of any given intervention will be substantially impacted by the extreme heterogeneity that characterizes ASD. It is therefore vital that future research seeks to identify the factors that influence the effectiveness of 
specific interventions for children with specific developmental profiles (Kasari \& Smith, 2016).

\section{Conclusions}

Severely impaired language acquisition and usage are common characteristics of ASD (Eigsti et al., 2011). Although the majority of individuals develop fluent expressive language, approximately $25 \%-30 \%$ have little or no functional speech during childhood (Anderson et al., 2007). ASD has been shown to impact important mechanisms that support language acquisition. At the population level, children with ASD have diminished preference for speech and atypical perceptual tuning to language (e.g. Filipe et al., 2017), and minimally verbal children have difficulty learning and understanding the meanings of words (e.g. Hartley \& Allen, 2014b, 2015b). The children who experience the greatest difficulty acquiring language tend to have more severe intellectual disabilities (Norrelgen et al., 2015) and greater abnormalities in brain structure and activation (e.g. Wan et al., 2012) than verbal peers. Development of expressive language in ASD is also strongly tied to early social communication, with superior skills in joint attention and symbolic play predicting greater linguistic outcomes concurrently and longitudinally (Luyster et al., 2008). While individuals with good verbal skills may be sensitive to social cues when learning words (at least in laboratory 
environments; Ellawadi \& McGregor, 2016), minimally verbal children have difficulty utilizing gaze and joint attention when mapping novel wordreferent relationships (Preissler \& Carey, 2005). Growing evidence suggests that NDBIs that integrate ABA principles with developmental theory represent a promising approach to targeting impairments in socialization and communication (Schreibman et al., 2015). By fostering the development of social-communicative precursors, NDBIs may also be effective at promoting language acquisition (Kasari et al., 2008), but more data concerning longterm outcomes are required to draw reliable comparisons to other approaches (e.g. highly structured DTT). Looking forward, it is vital that research continues to explore fundamental linguistic impairments in ASD to refine theoretical knowledge and inform the development of increasingly effective treatments. Further research is required to isolate the mechanisms that cause linguistic heterogeneity in ASD, and to identify the optimal environmental conditions that support language learning and development for children with different linguistic profiles. 


\section{References}

Abbeduto, L., \& Hesketh, L. J. (1997). Pragmatic development in individuals with mental retardation: Learning to use language in social interactions. Developmental Disabilities Research Reviews, 3(4), 323-333. doi:10.1002/(SICI)1098-2779(1997)3:4\%3C323::AIDMRDD7\%3E3.0.CO;2-O

Adamson, L. B. (1995). Communication development during infancy. Madison, WI: Brown \& Benchmark.

Akechi, H., Senju, A., Kikuchi, Y., Tojo, Y., Osanai, H., \& Hasegawa, T. (2011). Do children with ASD use referential gaze to learn the name of an object? An eye-tracking study. Research in Autism Spectrum Disorders, 5(3), 1230-1242. doi:10.1016/j.rasd.2011.01.013.

Allen, M. L., Hartley, C., \& Cain, K. (2015). Do iPads promote symbolic understanding and word learning in children with autism? Frontiers in Psychology, doi:10.3389/fpsyg.2015.00138

Allen, M. L., Hartley, C., \& Cain, K. (2016). iPads and the use of "apps" by children with autism spectrum disorder: Do they promote learning? Frontiers in Psychology. doi:10.3389/fpsyg.2016.01305 American Psychiatric Association. (2013). Diagnostic and statistical manual of mental health disorders (5th ed.). Washington, DC: Author. 
Anderson, D. K., Lord, C., Risi, S., DiLavore, P. S., Shulman, C., Thurm, A., ... Pickles, A. (2007). Patterns of growth in verbal abilities among children with autism spectrum disorder. Journal of Consulting and Clinical Psychology, 75, 594-604. doi:10.1037/0022-006X.75.4.594

Arunachalam, S., \& Luyster, R. J. (2016). The integrity of lexical acquisition mechanisms in autism spectrum disorders: A research review. Autism Research, 9(8), 810-828. doi:10.1002/aur.1590

Axelsson, E. L., Churchley, K., \& Horst, J. S. (2012). The right thing at the right time: Why ostensive naming facilitates word learning. Frontiers in Psychology, 3. doi:10.3389/fpsyg.2012.00088

Baghdadli, A., Picot, M. C., Michelon, C., Bodet, J., Pernon, E., Burstezjn, C., ... Aussilloux, C. (2007). What happens to children with PDD when they grow up? Prospective follow-up of 219 children from preschool age to mid-childhood. Acta Psychiatrica Scandinavica, 115(5), 403-412. doi:10.1111/j.1600-0447.2006.00898.x

Baldwin, D. A. (1991). Infants' contribution to the achievement of joint reference. Child Development, 62, 875-890. doi:10.2307/1131140

Baldwin, D. A. (1993). Early referential understanding: Infants' ability to recognize referential acts for what they are. Developmental Psychology, 29(5), 832-843. doi:10.1037/0012-1649.29.5.832 
Baron-Cohen, S., Baldwin, D. A., \& Crowson, M. (1997). Do children with autism use the speaker's direction of gaze strategy to crack the code of language? Child Development, 68, 48-57. doi:10.2307/1131924

Bartolucci, G., Pierce, S., \& Streiner, D. (1980). Cross-sectional studies of grammatical morphemes in autistic and mentally retarded children. Journal of Autism and Developmental Disorders, 10, 39-50. doi:10.1007/BF02408431

Bean Ellawadi, A., \& McGregor, K. K. (2016). Children with ASD can use gaze to map new words. International Journal of Language \& Communication Disorders, 51(2), 212-218. doi:10.1111/14606984.12192

Bedford, R., Gliga, T., Frame, K., Hudry, K., Chandler, S., Johnson, M. H., \& Charman, T. (2013). Failure to learn from feedback underlies word learning difficulties in toddlers at risk for autism. Journal of Child Language, 40(1), 29-46. doi:10.1017/S0305000912000086

Bloom, P. (2002). Mindreading, communication, and the learning of names for things. Mind and Language, 17(1-2), 37-54. doi:http://dx.doi.org/10.1111/1468-0017.00188.

Bondy, A., \& Frost, L. (2002). A picture's worth: PECS and other visual communication strategies in autism. Bethesda, MD: Woodbine House. 
Bonnel, A., McAdams, S., Smith, B., Berthiaume, C., Bertone, A., Ciocca, V., ... Mottron, L. (2010). Enhanced pure-tone pitch discrimination among persons with autism but not Asperger syndrome.

Neuropsychologia, 48(9), 2465-2475.

doi:10.1016/j.neuropsychologia.2010.04.020

Boucher, J. (2012). Research review: Structural language in autistic spectrum disorder - characteristics and causes. Journal of Child Psychology and Psychiatry, 53(3), 219-233. doi:10.1111/j.1469-7610.2011.02508.x

Brown, R. (1973). A first language: The early stages. Cambridge, MA: Harvard University Press.

Bruckner, C., Yoder, P., Stone, W., \& Saylor, M. (2007). Construct validity of the MCDI-I receptive vocabulary scale can be improved: Differential item functioning between toddlers with autism spectrum disorders and typically developing infants. Journal of Speech, Language, and Hearing Research, 50, 1631-1638. doi:10.1044/1092-4388(2007/110)

Bruner, J. S. (1983). Child's talk: Learning to use language. New York, NY: W. W. Norton \& Company.

Carey, S. (1978). The child as word learner. In M. Halle, J. Bresnan, \& G. A. Miller (Eds.), Linguistic theory and psychological reality (pp. 264293). Cambridge, MA: MIT Press. 
Charman, T., Drew, A., Baird, C., \& Baird, G. (2003). Measuring early language development in preschool children with autism spectrum disorder using the MacArthur Communicative Development Inventory (Infant Form). Journal of Child Language, 30(1), 213-236. doi:10.1017/S0305000902005482

Charman, T., Taylor, E., Drew, A., Cockerill, H., Brown, J. A., \& Baird, G. (2005). Outcome at 7 years of children diagnosed with autism at age 2: Predictive validity of assessments conducted at 2 and 3 years of age and pattern of symptom change over time. Journal of Child Psychology and Psychiatry, 4, 500-513. doi:10.1111/j.1469-7610.2004.00377.x

Chevallier, C., Kohls, G., Troiani, V., Brodkin, E. S., \& Schultz, R. T. (2012). The social motivation theory of autism. Trends in Cognitive Science, 16, 231-239. doi:10.1016/j.tics.2012.02.007

Curtin, S., \& Vouloumanos, A. (2013). Speech preference is associated with autistic-like behavior in 18-months-olds at risk for autism spectrum disorder. Journal of Autism and Developmental Disorders, 43(9), 21142120. doi:10.1007/s10803-013-1759-1

De Giacomo, A., \& Fombonne, E. (1998). Parental recognition of developmental abnormalities in autism. European Child \& Adolescent Psychiatry, 7, 131-136. doi:10.1007/s007870050058 
de Marchena, A., Eigsti, I.-M., Worek, A., Ono, K. E., \& Snedeker, J. (2011). Mutual exclusivity in autism spectrum disorders: Testing the pragmatic hypothesis. Cognition, 119(1), 96-113. doi:10.1016/j.cognition.2010.12.011

DiStefano, C., \& Kasari, C. (2016). The window to language is still open: Distinguishing between preverbal and minimally verbal children with ASD. Perspectives of the ASHA Special Interest Groups, 1(1), 4-11. doi:10.1044/persp1.SIG1.4

Droucker, D., Curtin, S., \& Vouloumanos, A. (2013). Linking infant-directed speech and face preferences to language outcomes in infants at risk for autism spectrum disorder. Journal of Speech, Language, and Hearing Research, 56(2), 567-576. doi:10.1044/1092-4388(2012/11-0266)

Dunn, L., \& Dunn, L. (2004). Peabody picture vocabulary test (4th ed.). Circle Pines, MN: AGS.

Dunn, L., Dunn, L., Sewell, J., Styles, B., Brzyska, B., Shamsan, Y., \& Burge, B. (2009). The British picture vocabulary scale (3rd ed.). London: GL Assessment.

Eigsti, I. M., \& Bennetto, L. (2009). Grammaticality judgments in autism: Deviance or delay? Journal of Child Language, 36, 999-1021. doi:10.1017/S0305000909009362 
Eigsti, I. M., Bennetto, L., \& Dadlani, M. B. (2007). Beyond pragmatics: Morphosyntactic development in autism. Journal of Autism and Developmental Disorders, 37, 1007-1023. doi:10.1007/s10803-006$0239-2$

Eigsti, I. M., \& Fein, D. A. (2013). More is less: Pitch discrimination and language delays in children with optimal outcomes from autism. Autism Research, 6(6), 605-613. doi:10.1002/aur.1324

Eigsti, I. M., de Marchena, A. B., Schuh, J. M., \& Kelley, E. (2011). Language acquisition in autism spectrum disorders: A developmental review. Research in Autism Spectrum Disorders, 5(2), 681-691. doi:10.1016/j.rasd.2010.09.001

Ellis Weismer, S., Gernsbacher, M. A., Stronach, S., Karasinski, C., Eernisse, E. R., Venker, C. E., \& Sindberg, H. (2011). Lexical and grammatical skills in toddlers on the autism spectrum compared to late talking toddlers. Journal or Autism and Developmental Disorders, 41(8), 10651075. doi:10.1007/s10803-010-1134-4

Ellis Weismer, S., \& Kover, S. T. (2015). Preschool language variation, growth, and predictors in children on the autism spectrum. Journal of Child Psychology and Psychiatry, 56(12), 1327-1337. doi:10.1111/jcpp.12406 
Elsabbagh, M., Divan, G., Koh, Y. J., Kim, Y. S., Kauchali, S., Marcín, C., ... Yasamy, M. T. (2012). Global prevalence of autism and other pervasive developmental disorders. Autism Research, 5(3), 160-179. doi:10.1002/aur.239

Fenson, L., Marchman, V. A., Thal, D. J., Reznick, S., \& Bates, E. (2006). The Macarthur-Bates Communicative Development Inventories: User's guide and technical manual (2nd ed.). Baltimore, MD: Paul H. Brookes Publishing.

Fernald, A. (1985). Four-month-old infants prefer to listen to motherese. Infant Behavior and Development, 8(2), 181-195. doi:10.1016/S01636383(85)80005-9

Fernell, E., Eriksson, M. A., \& Gillberg, C. (2013). Early diagnosis of autism and impact on prognosis: A narrative review. Clinical Epidemiology, 5, 33-43. doi:10.2147/CLEP.S41714

Ferster, C. B., \& DeMyer, M. K. (1962). A method for the experimental analysis of the behavior of autistic children. American Journal of Orthopsychiatry, 32, 89-98. doi:10.1111/j.1939-0025.1962.tb00267.x

Field, C., Allen, M. L., \& Lewis, C. (2016). Are children with autism spectrum disorder initially attuned to object function rather than shape for word learning? Journal of Autism and Developmental Disorders, 46, 1210-1219. doi:10.1007/s10803-015-2657-5 
Filipe, M. G., Watson, L., Vicente, S. G., \& Frota, S. (2017). Atypical preference for infant-directed speech as an early marker of autism spectrum disorders? A literature review and directions for further research. Clinical Linguistics \& Phonetics, 1-19. doi:10.1080/02699206.2017.1342694

Floccia, C., Keren-Portnoy, T., DePaolis, R., Duffy, H., Delle Luche, C., Durrant, S., . . Vihman, M. (2016). British English infants segment words only with exaggerated infant-directed speech stimuli. Cognition, 148, 1-9. doi:10.1016/j.cognition.2015.12.004

Friedrich, M., \& Friederici, A. D. (2011). Word learning in 6-month-olds: Fast encoding - weak retention. Journal of Cognitive Neuroscience, 23(11), 3228-3240. doi:10.1162/jocn_a_00002

Gernsbacher, M. A., Morson, E. M., \& Grace, E. J. (2015). Language development in autism. In G. Hickok \& S. Small (Eds.), Neurobiology of language (pp. 879-886). San Diego, CA: Elsevier.

Gernsbacher, M. A., Morson, E. M., \& Grace, E. J. (2016). Language and speech in autism. Annual Review of Linguistics, 2, 413-425. doi:10.1146/annurev-linguistics-030514-124824

Gernsbacher, M. A., \& Pripas-Kapit, S. (2012). Who's missing the point? A commentary on claims that autistic persons have a specific deficit in 
figurative language comprehension. Metaphor and Symbol, 27, 93-105. doi:10.1080/10926488.2012.656255

Gershkoff-Stowe, L., \& Smith, L. B. (2004). Shape and the first hundred nouns. Child Development, 75(4), 1098-1114. doi:10.1111/j.14678624.2004.00728.x

Gibson, E. J. (1973). Principles of perceptual learning and development. New York, NY: Appleton-Century-Crofts.

Gillespie-Lynch, K., Elias, R., Escudero, P., Hutman, T., \& Johnson, S. P. (2013). Atypical gaze following in autism: A comparison of three potential mechanisms. Journal of Autism and Developmental Disorders, 43(12), 2779-2792. doi:10.1007/s10803-013-1818-7

Gleitman, L. R., Newport, E. L., \& Gleitman, H. (1984). The current status of the motherese hypothesis. Journal of Child Language, 11(1), 43-79. doi:10.1017/S0305000900005584

Gliga, T., Elsabbagh, M., Hudry, K., Charman, T., Johnson, M., \& The BASIS Team. (2012). Gaze following, gaze reading, and word learning in children at risk for autism. Child Development, 83, 926-938. doi:10.1111/j.1467-8624.2012.01750.x

Goodwin, A., Fein, D., \& Naigles, L. R. (2012). Comprehension of whquestions precedes their production in typical development and autism 
spectrum disorders. Autism Research, 5, 109_123.

doi:10.1002/aur.1220

Griffin, R. (2002). Social learning in the non-social: Imitation, intentions, and autism. Developmental Science, 5(1), 30-32. doi:10.1111/14677687.00202

Gulsrud, A. C., Hellemann, G. S., Freeman, S. F., \& Kasari, C. (2014). Two to ten years: Developmental trajectories of joint attention in children with ASD who received targeted social communication interventions. Autism Research, 7(2), 207-215. doi:10.1002/aur.1360

Hampton, L. H., \& Kaiser, A. P. (2016). Intervention effects on spokenlanguage outcomes for children with autism: A systematic review and meta-analysis. Journal of Intellectual Disability Research, 60(5), 444463. doi:10.1111/jir.12283

Happé, F., \& Frith, U. (2006). The weak central coherence account: Detail focused cognitive style in autism spectrum disorders. Journal of Autism and Developmental Disorders, 36, 5-25. doi:10.1007/s10803-005-00390

Hartley, C., \& Allen, M. L. (2014a). Intentions vs. resemblance:

Understanding pictures in typical development and autism. Cognition, 131, 44-59. doi:10.1016/j.cognition.2013.12.009 
Hartley, C., \& Allen, M. L. (2014b). Generalisation of word-picture relations in children with autism and typically developing children. Journal of Autism and Developmental Disorders, 44, 2064-2071. doi:10.1007/s10803-014-2074-1

Hartley, C., \& Allen, M. L. (2015a). Is children's naming and drawing of pictures mediated by representational status? Evidence from typical development and autism. Cognitive Development, 36, 52-67. doi:10.1016/j.cogdev.2015.08.002

Hartley, C., \& Allen, M. L. (2015b). Symbolic understanding of pictures in low-functioning children with autism: The effects of iconicity and naming. Journal of Autism and Developmental Disorders, 45, 15-30. doi:10.1007/s10803-013-2007-4

Heaton, P., Hudry, K., Ludlow, A., \& Hill, E. (2008). Superior discrimination of speech pitch and its relationship to verbal ability in autism spectrum disorders. Cognitive Neuropsychology, 25(6), 771-782. doi:10.1080/02643290802336277

Horst, J. S., \& Samuelson, L. K. (2008). Fast mapping but poor retention by 24-month-old infants. Infancy, 13, 128-157. doi:10.1080/15250000701795598 
Horst, J. S., Scott, E. J., \& Pollard, J. A. (2010). The role of competition in word learning via referent selection. Developmental Science, 13, 706713. doi:10.1111/j.1467-7687.2009.00926.x

Howlin, P. (2003). Outcome in high-functioning adults with autism with and without early language delays: Implications for the differentiation between autism and Asperger syndrome. Journal of Autism and Developmental Disorders, 33(1), 3-13.

Howlin, P., Goode, S., Hutton, J., \& Rutter, M. (2004). Adult outcome for children with autism. Journal of Child Psychology and Psychiatry, 45(2), 212-229. doi:10.1111/j.1469-7610.2004.00215.x

Hudry, K., Leadbitter, K., Temple, K., Slonims, V., McConachie, H., Aldred, C., . . PACT Consortium. (2010). Preschoolers with autism show greater impairment in receptive compared to expressive language abilities. International Journal of Language \& Communication Disorders, 45, 681-690. doi:10.3109/13682820903461493

Järvinen-Pasley, A., Wallace, G. L., Ramus, F., Happé, F., \& Heaton, P. (2008). Enhanced perceptual processing of speech in autism. Developmental Science, 11(1), 109-121. doi:10.1111/j.14677687.2007.00644.x 
Johnson, C. P., \& Myers, S. M. (2007). Identification and evaluation of children with autism spectrum disorders. Pediatrics, 120(5), 1183-1215. doi:10.1542/peds.2007-2361

Jones, C. R., Happé, F., Baird, G., Simonoff, E., Marsden, A. J., Tregay, J., ... Charman, T. (2009). Auditory discrimination and auditory sensory behaviours in autism spectrum disorders. Neuropsychologia, 47(13), 2850-2858. doi:10.1016/j.neuropsychologia.2009.06.015

Kasari, C., Brady, N., Lord, C., \& Tager-Flusberg, H. (2013). Assessing the minimally verbal school-aged child with autism spectrum disorder. Autism Research, 6, 479-493. doi:10.1002/aur.1334

Kasari, C., Freeman, S., \& Paparella, T. (2006). Joint attention and symbolic play in young children with autism: A randomized controlled intervention study. Journal of Child Psychology and Psychiatry, 47(6), 611-620. doi:10.1111/j.1469-7610.2005.01567.x

Kasari, C., Paparella, T., Freeman, S., \& Jahromi, L. B. (2008). Language outcome in autism: Randomized comparison of joint attention and play interventions. Journal of Consulting and Clinical Psychology, 76(1), 125. doi:10.1037/0022-006X.76.1.125

Kasari, C., \& Smith, T. (2016). Forest for the trees: Evidence-based practices in ASD. Clinical Psychology: Science and Practice, 23(3), 260-264. doi:10.1111/cpsp.12161 
Kelley, E., Paul, J. J., Fein, D., \& Naigles, L. R. (2006). Residual language deficits in optimal outcome children with a history of autism. Journal of Autism and Developmental Disorders, 36, 897-928. doi:10.1007/s10803-006-0111-4

Kjelgaard, M. M., \& Tager-Flusberg, H. (2001). An investigation of language impairment in autism: Implications for genetic subgroups. Language and Cognitive Processes, 16(2-3), 287-308. doi:10.1080/01690960042000058

Klinger, L. G., \& Dawson, G. (2001). Prototype formation in autism. Development and Psychopathology, 13, 111-124. doi:10.1017/S0954579401001080

Koegel, L. K., Koegel, R. L., \& Smith, A. (1997). Variables related to differences in standardized test outcomes for children with autism. Journal of Autism and Developmental Disorders, 27(3), 233-243.

Kover, S. T., Edmunds, S. R., \& Ellis Weismer, S. (2016). Brief report: Ages of language milestones as predictors of developmental trajectories in young children with autism spectrum disorder. Journal of Autism and Developmental Disorders, 46(7), 2501-2507. doi:10.1007/s10803-0162756-y.

Kuhl, P. K., Coffey-Corina, S., Padden, D., Munson, J., Estes, A., \& Dawson, G. (2013). Brain responses to words in 2-year-olds with autism predict 
developmental outcomes at age 6. PLoS One, 8(5), e64967.

doi:10.1371/journal.pone.0064967

Kuhl, P. K., Conboy, B. T., Coffey-Corina, S., Padden, D., Rivera-Gaxiola, M., \& Nelson, T. (2008). Phonetic learning as a pathway to language:

New data and native language magnet theory expanded (NLM-e).

Philosophical Transactions of the Royal Society B: Biological Sciences, 363(1493), 979-1000. doi:10.1098/rstb.2007.2154

Kuhl, P. K., Williams, K. A., Lacerda, F., Stevens, K. N., \& Lindblom, B. (1992). Linguistic experience alters phonetic perception in infants by 6 months of age. Science, 255, 606-608. doi:10.1126/science.1736364

Landau, B., Smith, L. B., \& Jones, S. S. (1988). The importance of shape in early lexical learning. Cognitive Development, 3, 299-321. doi:10.1016/0885-2014(88)90014-7

Lind, S. E., \& Bowler, D. M. (2009). Recognition memory, self-other source memory, and theory-of-mind in children with autism spectrum disorder. Journal of Autism and Developmental Disorders, 39, 1231-1239. doi:10.1007/s10803-009-0735-2

Lombardo, M. V., Pierce, K., Eyler, L. T., Barnes, C. C., Ahrens-Barbeau, C., Solso, S., . . Courchesne, E. (2015). Different functional neural substrates for good and poor language outcome in autism. Neuron, 86(2), 567-577. doi:10.1016/j.neuron.2015.03.023 
Lord, C., Risi, S., \& Pickles, A. (2004). Trajectory of language development in autistic spectrum disorders. In M. L. Rice \& S. F. Warren (Eds.), Developmental language disorders: From phenotypes to etiologies (pp. 1-38). Mahwah, NJ: Lawrence Erlbaum Associates.

Lovaas, O. I., Ackerman, A. B., Alexander, D., Firestone, P., Perkins, J., \& Young, D. (1980). Teaching developmentally disabled children: The me book. Austin, TX: Pro-Ed.

Luyster, R. J., Kadlec, M. B., Carter, A., \& Tager-Flusberg, H. (2008).

Language assessment and development in toddlers with autism spectrum disorders. Journal of Autism and Developmental Disorders, 38(8), 1426-1438. doi:10.1007/s10803-007-0510-1

Luyster, R., Lopez, K., \& Lord, C. (2007). Characterizing communicative development in children referred for autism spectrum disorder using the Mac-Arthur Bates Communicative Development Inventory (CDI). Journal of Child Language, 34, 623-654. doi:10.1017/S0305000912000232

Luyster, R., \& Lord, C. (2009). Word learning in children with autism spectrum disorders. Developmental Psychology, 45(6), 1774-1786. doi:10.1037/a0016223

Markman, E. M. (1990). Constraints children place on word meanings. Cognitive Science, 14(1), 57-77. doi:10.1207/s15516709cog1401_4 
Markman, E. M., \& Wachtel, G. (1988). Children's use of mutual exclusivity to constrain the meaning of words. Cognitive Psychology, 20, 121-157. doi:10.1016/0010-0285(88)90017-5.

Martin, N. A., \& Brownell, R. (2011). Expressive One-Word Picture Vocabulary Test-4 (EOWPVT-4). Novato, CA: Academic Therapy Publications.

McConachie, H., Parr, J. R., Glod, M., Hanratty, J., Livingstone, N., Oono, I. P., . . Garland, D. (2015). Systematic review of tools to measure outcomes for young children with autism spectrum disorder: Systematic review of tools to measure outcomes for young children with autism spectrum disorder. Health Technology Assessment, 19(41), 1-506.

McDuffie, A., Yoder, P., \& Stone, W. (2005). Prelinguistic predictors of vocabulary in young children with autism spectrum disorders. Journal of Speech Language and Hearing Research, 48(5), 1080-1097. doi:10.1044/1092-4388(2005/075)

McGee, G. G., Krantz, P. J., \& McClannahan, L. E. (1985). The facilitative effects of incidental teaching on preposition use by autistic children. Journal of Applied Behavior Analysis, 18, 17-31. doi:10.1901/jaba.1985.18-17 
McGregor, K. K., \& Bean, A. (2012). How children with autism extend new words. Journal of Speech: Language, \& Hearing Research, 55, 70-83. doi:10.1044/1092-4388(2011/11-0024)

McGregor, K. K., Rost, G., Arenas, R., Farris-Trimble, A., \& Stiles, D. (2013). Children with ASD can use gaze in support of word recognition and learning. Journal of Child Psychology and Psychiatry, 54(7), 745753. doi: $10.1111 /$ jcpp. 12073

McGrew, J. H., Ruble, L. A., \& Smith, I. M. (2016). Autism spectrum disorder and evidence-based practice in psychology. Clinical Psychology: Science and Practice, 23, 239-255. doi:10.1111/cpsp. 12160

McMurray, B., Horst, J. S., \& Samuelson, L. K. (2012). Word learning emerges from the interaction of online referent selection and slow associative learning. Psychological Review, 119, 831-877. doi:10.1037/a0029872

Miller, J., \& Chapman, R. (2000). Systematic Analysis of Language Transcripts (SALT). Madison, WI: University of Wisconsin, Waisman Center.

Mottron, L., Dawson, M., Soulières, I., Hubert, B., \& Burack, J. (2006). Enhanced perceptual functioning in autism: An update, and eight 
principles of autistic perception. Journal of Autism and Developmental Disorders, 36, 27-43. doi:10.1007/s10803-005-0040-7

Mullen, E. M. (1995). Mullen scales of early learning: AGS edition. Circle Pines, MN: American Guidance Service.

Mundy, P., Sigman, M., \& Kasari, C. (1990). A longitudinal study of joint attention and language development in autistic children. Journal of Autism and Developmental Disorders, 20(1), 115-128. doi:10.1007/BF02206861

Nadig, A. S., Ozonoff, S., Young, G. S., Rozga, A., Sigman, M., \& Rogers, S. J. (2007). A prospective study of response to name in infants at risk for autism. Archives of Pediatrics \& Adolescent Medicine, 161(4), 378383. doi:10.1001/archpedi.161.4.378

Naigles, L. R., Kelty, E., Jaffery, R., \& Fein, D. (2011). Abstractness and continuity in the syntactic development of young children with autism. Autism Research, 4(6), 422-437. doi:10.1002/aur.223

Naigles, L. R., \& Tek, S. (2017). "Form is easy, meaning is hard" revisited: (re) characterizing the strengths and weaknesses of language in children with autism spectrum disorder. Wiley Interdisciplinary Reviews: Cognitive Science. doi:10.1002/wcs.1438

Nappa, R., Wessel, A., McEldoon, K. L., Gleitman, L. R., \& Trueswell, J. C. (2009). Use of speaker's gaze and syntax in verb learning. Language 
Learning and Development, 5(4), 203-234.

doi:10.1080/15475440903167528

Norbury, C. F. (2005). The relationship between theory of mind and metaphor: Evidence from children with language impairment and autistic spectrum disorder. British Journal of Developmental Psychology, 23, 383-399. doi:10.1348/026151005X26732

Norbury, C. F., Griffiths, H., \& Nation, K. (2010). Sound before meaning: Word learning in autistic disorders. Neuropsychologia, 48(14), 40124019. doi:10.1016/j.neuropsychologia.2010.10.015

Norrelgen, F., Fernell, E., Eriksson, M., Hedvall, Å., Persson, C., Sjölin, M., .. Kjellmer, L. (2015). Children with autism spectrum disorders who do not develop phrase speech in the preschool years. Autism, 19(8), 934-943. doi:10.1177/1362361314556782

Obeid, R., Brooks, P. J., Powers, K. L., Gillespie-Lynch, K., \& Lum, J. A. (2016). Statistical learning in specific language impairment and autism spectrum disorder: A meta-analysis. Frontiers in Psychology, 7, 1245. doi:10.3389/fpsyg.2016.01245

Osterling, J. A., Dawson, G., \& Munson, J. A. (2002). Early recognition of 1year-old infants with autism spectrum disorder versus mental retardation. Development and Psychopathology, 14, 239-251. doi:10.1017/S0954579402002031 
Ozonoff, S., Cook, I., Coon, H., Dawson, G., Joseph, R. M., Klin, A., . . . Rogers, S. J. (2004). Performance on Cambridge neuropsychological test automated battery subtests sensitive to frontal lobe function in people with autistic disorder: Evidence from the Collaborative Programs of Excellence in Autism network. Journal of Autism and Developmental Disorders, 34(2), 139-150. doi:10.1023/B:JADD.0000022605.81989.cc

Parish-Morris, J., Hennon, E. A., Hirsh-Pasek, K., Golinkoff, R. M., \& TagerFlusberg, H. (2007). Children with autism illuminate the role of social intention in word learning. Child Development, 78, 1265-1287. doi:10.1111/j.1467-8624.2007.01065.x

Paul, R., Chawarska, K., Fowler, C., Cicchetti, D., \& Volkmar, F. (2007). "Listen my children and you shall hear": Auditory preferences in toddlers with autism spectrum disorders. Journal of Speech, Language, and Hearing Research, 50(5), 1350-1364. doi:10.1044/1092$4388(2007 / 094)$

Perry, L. K., \& Samuelson, L. K. (2011). The shape of the vocabulary predicts the shape of the bias. Frontiers in Psychology, 2, 345. doi:10.3389/fpsyg.2011.00345

Piaget, J. (1966). Psychology of intelligence. Totowa, NJ: Littlefield, Adams, \& Co. 
Pickles, A., Anderson, D. K., \& Lord, C. (2014). Heterogeneity and plasticity in the development of language: A 17 year follow up of children referred early for possible autism. Journal of Child Psychology and Psychiatry, 55(12), 1354-1362. doi:10.1111/jcpp.12269

Pickles, A., Le Couteur, A., Leadbitter, K., Salomone, E., Cole-Fletcher, R., Tobin, H., ... \& Aldred, C. (2016). Parent-mediated social communication therapy for young children with autism (PACT): longterm follow-up of a randomised controlled trial. The Lancet, 388(10059), 2501-2509. doi:10.1016/S0140-6736(16)31229-6

Potrzeba, E. R., Fein, D., \& Naigles, L. (2015). Investigating the shape bias in typically developing children and children with autism spectrum disorders. Frontiers in Psychology, 6, 446.

doi:10.3389/fpsyg.2015.00446

Preissler, M. A., \& Carey, S. (2005). What is the role of intentional inference in word learning? Evidence from autism. Cognition, 97, B13-B23. doi:10.1016/j.cognition.2005.01.008

Prizant, B. M. (1996). Brief report: Communication, language, social, and emotional development. Journal of Autism and Developmental Disorders, 26, 173-178. doi:10.1007/BF02172007

Quine, W. V. O. (1960). Word and object: An inquiry into the linguistic mechanisms of objective reference. Cambridge, MA: MIT Press. 
Risley, T., \& Wolf, M. (1967). Establishing functional speech in echolalic children. Behaviour Research and Therapy, 5, 71-88. doi:10.1016/0005-7967(67)90001-0

Riva, D., Bulgheroni, S., Aquino, D., Di Salle, F., Savoiardo, M., \& Erbetta, A. (2011). Basal forebrain involvement in low-functioning autistic children: A voxel-based morphometry study. American Journal of Neuroradiology, 32(8), 1430-1435. doi:10.3174/ajnr.A2527

Roberts, J. A., Rice, M. L., \& Tager-Flusberg, H. (2004). Tense marking in children with autism. Applied Psycholinguistics, 29, 429-448. doi:10.1017/S0142716404001201

Rose, V., Trembath, D., Keen, D., \& Paynter, J. (2016). The proportion of minimally verbal children with autism spectrum disorder in a community-based early intervention programme. Journal of Intellectual Disability Research, 60(5), 464-477. doi:10.1111/jir.12284

Roser, M. E., Aslin, R. N., McKenzie, R., Zahra, D., \& Fiser, J. (2015). Enhanced visual statistical learning in adults with autism. Neuropsychology, 29(2), 163. doi:10.1037/neu0000137.

Rutter, M. (1978). Diagnosis and definitions of childhood autism. Journal of Autism and Childhood Schizophrenia, 8, 139-161. doi:10.1007/BF01537863 
Samuelson, L., \& Smith, L. B. (1999). Early noun vocabularies: Do ontology, category structure, and syntax correspond? Cognition, 71, 1-33. doi:10.1016/S0010-0277(99)00034-7.

Schreibman, L., Dawson, G., Stahmer, A. C., Landa, R., Rogers, S. J., McGee, G. G., . . McNerney, E. (2015). Naturalistic developmental behavioral interventions: Empirically validated treatments for autism spectrum disorder. Journal of Autism and Developmental Disorders, 45(8), 2411-2428. doi:10.1007/s10803-015-2407-8

Shire, S. Y., Chang, Y. C., Shih, W., Bracaglia, S., Kodjoe, M., \& Kasari, C. (2017). Hybrid implementation model of community-partnered early intervention for toddlers with autism: A randomized trial. Journal of Child Psychology and Psychiatry, 58(5), 612-622.

doi:10.1111/jcpp.12672

Shultz, S., \& Vouloumanos, A. (2010). Three-month-olds prefer speech to other naturally occurring signals. Language Learning and Development, 6(4), 241-257. doi:10.1080/15475440903507830

Singh, L., Nestor, S., Parikh, C., \& Yull, A. (2009). Influences of infantdirected speech on early word recognition. Infancy, 14(6), 654-666. doi:10.1080/15250000903263973 
Smith, L. B., Jones, S. S., Landau, B., Gershkoff-Stowe, L., \& Samuelson, L. (2002). Object name learning provides on-the-job training for attention. Psychological Science, 13, 13-19. doi:10.1111/1467-9280.00403

Son, J. Y., Smith, L. B., \& Goldstone, R. L. (2006). Generalizing from simple instances: An uncomplicated lesson from kids learning object categories. In Proceedings of the twenty-eighth annual conference of the cognitive science society. Hillsdale, NJ: Lawrence Erlbaum Associates.

Sparrow, S., Cicchetti, D., \& Balla, D. (2005). Vineland adaptive behavior scales (2nd ed.). Circle Pines, MN: AGS.

Swensen, L. D., Kelley, E., Fein, D., \& Naigles, L. R. (2007). Processes of language acquisition in children with autism: Evidence from preferential looking. Child Development, 78(2), 542-557. doi:10.1111/j.1467-8624.2007.01022.x

Tager-Flusberg, H., \& Calkins, S. (1990). Does imitation facilitate acquisition of grammar? Evidence from the study of autistic, Down's syndrome and normal children. Journal of Child Language, 17, 591-606. doi:10.1017/S0305000900010898

Tager-Flusberg, H., \& Kasari, C. (2013). Minimally verbal school-aged children with autism spectrum disorder: The neglected end of the spectrum. Autism Research, 6, 468-478. doi:10.1002/aur.1329 
Tager-Flusberg, H., Paul, R., \& Lord, C. E. (2005). Language and communication in autism. In F. Volkmar, R. Paul, A. Klin, \& D. J. Cohen (Eds.), Handbook of autism and pervasive developmental disorder, Third Edition Volume 1 (pp. 335-364). New York, NY: Wiley-Blackwell.

Tager-Flusberg, H., \& Joseph, R. M. (2003). Identifying neurocognitive phenotypes in autism. Philosophical Transactions of the Royal Society B: Biological Sciences, 358, 303-314. doi:10.1098/rstb.2002.1198

Tager-Flusberg, H., Rogers, S., Cooper, J., Landa, R., Lord, C., Paul, R., . . . Yoder, P. (2009). Defining spoken language benchmarks and selecting measures of expressive language development for young children with autism spectrum disorders. Journal of Speech, Language, and Hearing Research, 52(3), 643-652. doi:10.1044/1092-4388(2009/08-0136)

Taylor, M. J., Charman, T., Robinson, E. B., Hayiou-Thomas, M. E., Happé, F., Dale, P. S., \& Ronald, A. (2014). Language and traits of autism spectrum conditions: Evidence of limited phenotypic and etiological overlap. American Journal of Medical Genetics Part B:

Neuropsychiatric Genetics, 165(7), 587-595. doi:10.1002/ajmg.b.32262

Tek, S., Jaffery, G., Fein, D., \& Naigles, L. R. (2008). Do children with autism spectrum disorders show a shape bias in word learning? Autism Research, 1, 208-222. doi:10.1002/aur.38 
Tek, S., Mesite, L., Fein, D., \& Naigles, L. (2014). Longitudinal analyses of expressive language development reveal two distinct language profiles among young children with autism spectrum disorders. Journal of Autism and Developmental Disorders, 44(1), 75-89. doi:10.1007/s10803-013-1853-4

Tenenbaum, E. J., Amso, D., Righi, G., \& Sheinkopf, S. J. (2017). Attempting to "increase intake from input": Attention and word learning children with autism. Journal of Autism and Developmental Disorders, 47(6), 1791-1805. doi:10.1007/s10803-017-3098-0

Thurm, A., Lord, C., Lee, L-C., \& Newschaffer, C. (2007). Predictors of language acquisition in preschool children with autism spectrum disorders. Journal of Autism and Developmental Disorders, 37(9), 1721-1734. doi:10.1007/s10803-006-0300-1

Tomasello, M., Strosberg, R., \& Akhtar, N. (1996). Eighteen-month-old children learn words in non-ostensive contexts. Journal of Child Language, 23(1), 157-176. doi:10.1017/S0305000900010138

Twomey, K. E., Ranson, S. L., \& Horst, J. S. (2014). That's more like it: Multiple exemplars facilitate word learning. Infant and Child Development, 23, 105-122. doi:10.1002/icd.1824 
Vouloumanos, A., \& Curtin, S. (2014). Foundational tuning: How infants' attention to speech predicts language development. Cognitive Science, 38(8), 1675-1686. doi:10.1111/cogs.12128

Vouloumanos, A., \& Werker, J. F. (2007). Listening to language at birth: Evidence for a bias for speech in neonates. Developmental Science, 10(2), 159-164. doi:10.1111/j.1467-7687.2007.00549.x

Vygotsky, L. (1978). Mind in society: The development of higher psychological processes. Cambridge, MA: Harvard University Press.

Wan, C. Y., Marchina, S., Norton, A., \& Schlaug, G. (2012). Atypical hemispheric asymmetry in the arcuate fasciculus of completely nonverbal children with autism. Annals of the New York Academy of Sciences, 1252(1), 332-337. doi:10.1111/j.1749-6632.2012.06446.x

Warren, S. F., Gilkerson, J., Richards, J. A. (2010). What automated vocal analysis reveals about the vocal production and language learning environment of young children with autism. Journal of Autism and Developmental Disorders, 40(5), 555-569. doi:10.1007/s10803-009$0902-5$

Waterhouse, L., \& Fein, D. (1982). Language skills in developmentally disabled children. Brain and Language, 15(2), 307-333. doi:10.1016/0093-934X(82)90062-1 
Watson, L. R., Baranek, G. T., Roberts, J. E., David, F. J., \& Perryman, T. Y. (2010). Behavioral and physiological responses to child-directed speech as predictors of communication outcomes in children with autism spectrum disorders. Journal of Speech, Language, and Hearing Research, 53(4), 1052-1064. doi:10.1044/1092-4388(2009/09-0096)

Weisleder, A., \& Fernald, A. (2013). Talking to children matters: Early language experience strengthens processing and builds vocabulary. Psychological Science, 24, 2143-2152. doi:10.1177/0956797613488145

Werker, J. F., \& Tees, R. C. (1999). Influences on infant speech processing: Toward a new synthesis. Annual Review of Psychology, 50(1), 509535. doi:10.1146/annurev.psych.50.1.509

Wetherby, A. M., Guthrie, W., Woods, J., Schatschneider, C., Holland, R. D., Morgan, L., \& Lord, C. (2014). Parent-implemented social intervention for toddlers with autism: An RCT. Pediatrics, 134, 1084-1093. doi:10.1542/peds.2014-0757

Woynaroski, T., Watson, L., Gardner, E., Newsom, C. R., Keceli-Kaysili, B., \& Yoder, P. J. (2016). Early predictors of growth in diversity of key consonants used in communication in initially preverbal children with autism spectrum disorder. Journal of Autism and Developmental Disorders, 46(3), 1013-1024. doi:10.1007/s10803-015-2647-7 
Yoder, P., Watson, L. R., \& Lambert, W. (2015). Value-added predictors of expressive and receptive language growth in initially nonverbal preschoolers with autism spectrum disorders. Journal of Autism and Developmental Disorders, 45(5), 1254-1270. doi:10.1007/s10803-0142286-4.

Younger, B. (1990). Infant categorization: Memory for category-level and specific item information. Journal of Experimental Child Psychology, 50, 131-155. doi:10.1016/0022-0965(90)90036-8 